\title{
ATOMIC WEAPONS*
}

$I^{\mathrm{N}}$ ordinary explosives, energy is released at high speed as a result of the rearrangement of unstable molecules into more stable forms. Since the energy is of the same order of magnitude for all chemical reactions, chemical explosives much more powerful than those available at present will never be found. In atomic weapons, however, energy is generated by the rearrangement of particles in the atomic nuclei. Nuclei are always lighter than their constituent particles, and this mass defect is a measure of the energy that would be liberated if the nucleus could be built up from its components. Since the mass defect is greatest for elements of medium atomic weight, there are two possible sources of atomic energy, namely, the building up of nuclei of medium elements from lighter ones and the breaking down of heavy elements to medium ones. The latter is the fission process on which the atom bomb is based.

To produce an explosion, the release of energy must be practically instantaneous. The fission of uranium-235 or plutonium-239 can be made to fulfil this requirement if a chain reaction is set up propagated by fast neutrons. At each fission, two or three fast neutrons are liberated, and if the mass of the fissile material is great enough to ensure that more than one of these neutrons produces further fission, a chain reaction is initiated which runs its course in a few millionths of a second, producing a shock wave of unprecedented destructive force.

In January 1950, the President of the United States announced that he had directed the continuation of work on all forms of weapons "including the so-called hydrogen bomb". This made public the possibility of producing energy by the fusion of light

* Summary of a lecture by Prof. O. R. Frisch, O.B.E., F.R.S., being the second of the series of public lectures arranged by the Atomic Scientists' Association and the Department of Extra-Mural
the Cniversity of London (see Nature, February 27, p. 386). elements into heavy ones. In January 1953 it was announced that a thermonuclear test had taken place at Eniwetok, and in August 1953 Malenkov stated that "the U.S. no longer has the monopoly of the hydrogen bomb".

Little is known publicly about the construction of the hydrogen bomb; but most probably it is based on the fusion of hydrogen nuclei into helium nuclei, taking place at very high temperatures. The temperatures necessary for such reaction are of the order of millions of degrees and can only be produced by a fission bomb; the hydrogen bomb must thus be triggered by a fission bomb. It is fairly certain that hydrogen is the main material for a thermonuclear bomb, for the fusion of heavier elements requires much higher temperatures and produces less energy; but ordinary hydrogen is not suitable, and either deuterium or tritium have to be used.

The main advantage of the hydrogen bomb is that there is no essential limit to its size. It is a very safe explosive, for it will never go off unless fired by the fission bomb. The latter, on the other hand, is by nature unsafe and goes off the instant it is assembled, which puts a practical limit to its size. The load capacity of modern aircraft would, however, limit the explosive power of the hydrogen bomb to about a thousand times that of the fission bomb. The radius of damage of such explosive would thus be ten times greater than that of a fission bomb, that is, about ten miles for severe damage.

Against the background of Nature, atomic weapons are small. An average local thunderstorm releases as much energy as a plutonium bomb ; a hurricane or an earthquake, a million times as much. Nevertheless, they are frightful weapons, capable of inflieting terrible destruction and wholesale death.

\section{MANAGEMENT OF PUBLIC CORPORATIONS}

T HE Select Committee appointed in December 1951 "to consider the present methods by which the House of Commons is informed of the affairs of the Nationalized Industries and to report what changes, having regard to the provisions laid down by Parliament in the relevant statutes, may be desirable in these methods" issued last year a second report* which indicates very clearly how far we yet are from a satisfactory solution to the problem of parliamentary accountability. The Committee's first report was confined to the Parliamentary 'question' and stressed the limitations of this method of keeping Parliament informed and securing public accountability, rather than offering a fresh contribution towards the solution of what is increasingly recognized as a problem of national importance. In this first report, it was apparent from the evidence submitted to the Committee that, while the import-

* Report from the Select Committee on Nationalized Industries, together with the Proceedings of the Committee, Minutes of Evidence and an Appendix. Pp. xviii + 118. (London: H.M. Stationery Office, 1953.) 48. net. ance of the public issues involved is widely appreciated, there is also a considerable difference of opinion as to the means for improving the present unsatisfactory situation, and also some misunderstanding as to the possibility of reconciling in a practicable way the independence and flexibility which are essential if a public corporation is to be characterized by initiative and enterprise, with complete answerability to Parliament.

This is also characteristic of the Select Committee's second report. The clash of opinion is no less marked, and the Committee's recommendations are obviously contrary to the opinions, strongly held and sometimes vehemently expressed, of important witnesses. The value of the report may well lie in the material for critical examination and further constructive thinking which it affords in its minutes of evidence, rather than in its somewhat tentative recommendations. The most encouraging feature of the report is, in fact, the indication it supplies of a disposition to examine the whole problem objectively and to keep 